\title{
Communicating fatigue in general practice and the role of gender ${ }^{\text {ts }}$
}

\author{
Ludwien Meeuwesen $^{\mathrm{a}, *}$, Jozien Bensing ${ }^{\mathrm{b}}$, Atie van den Brink-Muinen ${ }^{\mathrm{b}}$ \\ ${ }^{a}$ Department of General Social Sciences, Research Institute for Psychology and Health, Utrecht University, \\ P.O. Box 80.140, 3508 TC, Utrecht, The Netherlands \\ ${ }^{\mathrm{b}}$ NIVEL, Netherlands Institute for Health Services Research, Research Institute for Psychology and Health, \\ Utrecht, The Netherlands
}

\begin{abstract}
The aim of this study has been to obtain more insight into the health condition of fatigued patients, their expectations when visiting the general practitioner (GP), the way they communicate, and possible gender differences. Data consisted of 579 patient questionnaires and 440 video-observations of these patients and 31 GPs. Results showed that fatigue is a common health problem but seldom on the agenda in general practice. More women indicated symptoms of fatigue than men did. Fatigued patients' health was worse than that of non-fatigued patients, and they expected more biomedical and especially psychosocial communication. Furthermore, male fatigued patients expected more biomedical communication than fatigued female patients did. While the GPs accommodated their verbal behavior to fatigued patients by giving more psychosocial information and more counseling, they were not more affective towards the fatigued than towards the non-fatigued patients. Female GPs were more affective than their male colleagues, and they used gender-specific communication strategies to explore the patient's agenda. It seems necessary to use a gender-sensitive approach in communication research.
\end{abstract}

(C) 2002 Elsevier Science Ireland Ltd. All rights reserved.

Keywords: General practice; Symptoms of fatigue; Doctor-patient communication; Gender communication; Health perception; Patient expectations

\section{Introduction}

This study focuses on fatigue as a health problem and the way it is communicated during medical visits at the general practitioner's (GP's) surgery. In western societies, fatigue has been found to be a common health problem in the population, as well as in general practice. Depending on definition and measurement instruments, between 7 and $45 \%$ of the general population report fatigue [1]. Not all fatigue complaints come to the attention of general practitioners because they are either not reported by the patient or not recorded by the general practitioner [2]. In The Netherlands, 'fatigue' is recorded as the reason for encounter for only $6.3 \%$ of the patients in general practice [3], whereas in a population study, $29 \%$ of the respondents complained about fatigue during the 14 days before the interview [4]. Thus, although fatigue is a common problem, in general practice it is often not discussed or is ignored. If fatigue complaints become chronic, they may seriously affect the patient's

\footnotetext{
th This article is based on data of the Eurocommunication study, which has been made possible by funding from the BIOMED-II research programme of the European Union (contract no. BMH4-CT96-1515).

* Corresponding author. Tel.: +31-30-2531-408; fax: +31-30-2534-733. E-mail address: 1.meeuwesen@fss.uu.nl (L. Meeuwesen).
}

quality of life, which leads to high costs in health care and frustrating diagnostic and therapeutic interventions [5].

The problem of fatigue has many faces. It is difficult to define, as it is both an intrinsic part of life and a medical problem. There is no universal test for fatigue, and it is generally assumed that the individual report of fatigue is the only measure to rely on. Fatigue can be a primary complaint or secondary to a known disorder, as is most often the case in chronic diseases. There are a variety of causes of fatigue, ranging from psychological (e.g. depression), through physical diseases (e.g. viral infections or anemia), to aspects of the patient's life world (e.g. overwork or too little activity) [6]. However, most often we have to do with a complex interaction of psychological, physical and social aspects, as a result of a process of interpretation and labeling, in which self-perceptions and basic knowledge of diseases interact in a highly individualized way [7]. Fatigued people subjectively perceive their health as poorer than non-fatigued people do [8]. Quite extreme is the condition of 'burnout' where the experience of the draining of emotional resources is strongly related to the feeling of fatigue. It is mostly applied to employed young adults having problems at work and/or other social problems [9]. If there is no adequate care for these groups of people, a considerable number of them will become chronically disabled, which has many negative 
consequences on a personal as well as a societal level. The Netherlands sees an intensive social debate, because nearly 1 million people are work-disabled here, and $30 \%$ of them for psychosocial reasons or because of 'burnout'. It is remarkable that the recent rapid increase of burnout concerns women [10]. Generally, women complain more about fatigue than men do $[11,12]$, especially when they are young and highly educated [8]. Having to combine employment with child-care, women constitute a fatigue-syndrome riskgroup. However, they are only slightly more likely to present fatigue as a complaint to their physician [12].

Although there is an increase in knowledge over the past years regarding epidemiology, causes, perceptions, and experiences of fatigue, the way patients and doctors communicate about fatigue remains still quite unknown as a scientific issue. Because most of the time fatigue cannot be diagnosed objectively, for instance by means of laboratory tests [12], the only way to understand the patient's fatigue is by listening to the patient and by paying attention to his/her complaints. Adequate doctor-patient communication is considered of utmost importance in the process of guiding patients with complaints of fatigue, and it involves affective and instrumental behavior. When patients are sicker or emotionally more distressed, medical communication seems to be even more complicated [13]. In order to stimulate patients to disclose their concerns, it is necessary to establish adequate patient-centered communication [5,14]. The instrumental communication (questions, answers, information gathering, counseling) will help the doctor to get a more complete picture of the patient's complaints and to propose an effective treatment. Affective behavior of the physician, such as empathy, contributes substantially to the patient's satisfaction and quality of care [5], by fulfilling the patient's need to be recognized and understood. Patients have two basic needs: the cognitive need to be informed and the emotional need to be taken seriously [15]. In the case of fatigue or psychosocial problems, patients may expect more at the emotional level, which results in a stronger appeal to the affective behavior of the doctors. Patients need enough room to report their problems and to feel that they are taken seriously. Affective behavior is also an essential element in technical-medical care, e.g. the physician's affective behavior has also a facilitating effect on the information exchange between the patient and the GP [5]. Depending on the specific needs of the patient, a balance between affective and instrumental behavior has to be found.

For many reasons doctors differ from one another in their communicative styles. One of these differences has to do with gender. It is repeatedly confirmed that male physicians show more controlling and directive behavior, while female doctors are more attentive and non-directive [16]. Female doctors pay more attention to a good relationship with the patient and counsel more frequently about psychosocial aspects of the complaints compared to male doctors [16-19]. They also prescribe less medication, and attend more to the feelings and experiences of the patients $[20,21]$. In sum, female doctors as a group seem to be more patient-centered, especially with female patients. If female patients have a possibility to choose, they tend to prefer a female doctor [22]. What is 'gendered' is not only the prevalence of fatigue, but also the physician's behavior. By their patient-centered style, female doctors may be more sensitive to the specific needs of fatigued patients. The aim of this study is to gain more insight, besides general factors, into the specific role of gender in communicating fatigue in general practice.

The research questions that will be dealt with are:

1. How many patients feel fatigued when consulting a GP, and what is their health status? Are there gender differences?

2. What do fatigued patients expect from the communication aspect of the medical visit, compared to nonfatigued patients? Are there gender differences?

3. Are there any differences in communication styles between fatigued and non-fatigued patients? Are there gender differences?

4. Are there any communication differences among GPs in relation to patients' level of fatigue? Are there gender differences among GPs?

While there is a gap in the prevalence of fatigue in the population and in complaining about fatigue in medical consultation, it seems relevant to investigate the specific role of gender, besides general factors. On the basis of the relevant literature, it is hypothesized that many patients will experience feelings of fatigue, and that their health condition will be worse. They will expect more communication with the GP, both instrumentally - because of the ambiguity and uncertainties in fatigue - and emotionally. This tendency will be stronger for female patients regarding female doctors. We also expect an effect of gender on the communication process, with female doctors tending to be more sensitive to the needs of the fatigued patients.

\section{Method}

\subsection{Subjects and procedures}

The study has been based on data of 579 patients and 31 doctors, being the Dutch part of the Eurocommunication study $[23,24]$. Collecting data of patients' fatigue complaints was limited to the Dutch sample. For the Dutch part of the Eurocommunication study, 31 GPs (15 male and 16 female) were included in the study, having signed informed consent forms before the data collection started. The mean age of the GPs was 45 years (youngest 32 years, oldest 62 years).

Consecutive patients of all ages consulting the GP on the day of data collection were approached and asked for a written informed consent before the consultation. Patients were free to cooperate or not. About $16 \%$ of the patients refused to participate. The patient sample $(n=579)$ consisted of 223 men and 356 women. There were nearly twice 
as many female patients as there were male patients $(61.5$ and $38.5 \%$, respectively). The seven most frequently presented health problems were respiratory, musculoskeletal, dermatological, general, digestive, circulatory, and neurological. The mean age of the patients was $X=40.4$ $($ S.D. $=21.4)$, within a range between 0 and 93 years; and $51.5 \%$ was between 19 and 50 years. The majority of the patients had a low $(27.2 \%)$ or average $(47.7 \%)$ educational background and $25 \%$ was highly educated.

The gender division of GPs and patients was as follows. Regarding the male GPs, the data of 117 male patients $(20 \%)$ and 162 female patients (28\%) were included. Of the female GPs, the data consisted of 106 male patients (18\%) and 194 female patients $(34 \%)$. The overrepresentation of female patients was stronger in the case of female GPs.

\subsection{Measures}

The data were gathered by 579 patient questionnaires and 440 observations of doctor-patient communication encounters. The patient questionnaire contained the following measurements.

\subsubsection{Feeling fatigued}

Respondents were asked to indicate whether they had suffered fatigue during the previous 2 weeks or not. This question was derived from a list of acute complaints which is frequently used and validated in The Netherlands $[8,25,26]$. If the answer was 'yes', they were asked to indicate the level of fatigue on a scale between 0 and 10 . In order to get a more refined analysis, the group of fatigued patients was subdivided. A cut-off score of 5/6 was taken (which was based on the mean score and the median), meaning 'mildly fatigued' up to 5, and 'considerably fatigued' from 6 to 10. Analyses were executed with three groups reporting different levels of fatigue: (1) not fatigued at all, (2) mildly fatigued, and (3) considerably fatigued. It was registered if fatigue was discussed or not in the medical consultation, and if it was coded as 'the reason for encounter' and/or 'the diagnosis' according to the International Classification of Primary Care (ICPC) [27]. The reliability of the coding was satisfactory [27].

\subsubsection{Health and health perception}

For measuring the patients' physical, emotional and social functioning, the COOP/WONCA charts were used [28]. This validated questionnaire included seven items which referred to the past 2 weeks: physical illness, feelings, daily activities, social activities, change in health, pain and overall health. The questionnaire was rated on a 5-point Likert scale $(1=$ very good, $5=$ very bad $)$. Also a total score 'health condition' was computed, based on the seven items.

\subsubsection{Consultation expectations}

For measuring the patient's expectations regarding the specific medical encounter a scale was used, based on the combining and adaptation of the Quote scale [29] and the 'Patient Requests Form' (PRF) [24,30]. The questionnaire used here contained 14 items, and revealed three sub-scales: a biomedical scale, a psychosocial scale, and an investigation and treatment scale. The biomedical scale (six items) consisted of items related to discussing symptoms and problems, and explaining test results and the course and seriousness of problems. The psychosocial scale (four items) comprised items related to emotional support and explanation of psychosocial problems. The investigation and treatment scale (four items) contained items indicating diagnosis, medication, and referral. The reliability in terms of Cronbach's $\alpha$ was: biomedical scale, $\alpha=0.83$; psychosocial scale, $\alpha=0.83$; and treatment scale, $\alpha=0.54$. The importance of the various items for the patient's visit of that day was assessed on a 4-point scale (not important, rather important, important, of utmost importance), plus a possibility to tick the item as 'non-applicable'. The percentages of patients who assessed an item as '(of utmost) importance' were the indicator for the importance score.

\subsubsection{Affective and instrumental behavior}

Analysis of verbal behavior was based on video records of doctor-patient consultations. Of all patients, a total of 440 videos was available. The division of these groups of patients in terms of gender, age, and educational level was the same as for the whole group. Verbal affective and instrumental behavior was measured by means of Roter's Interaction Analysis System (RIAS) [23,24,31]. This system, which was based on the work of Bales [32], is well-documented and widely used in the USA and The Netherlands for coding both doctor and patient communication. This system distinguishes both instrumental (task-focused) and affective (socio-emotional) verbal behavior in doctors and patients, reflecting the cure-care dimension. The RIAS enables the identification, categorization, and quantification of salient features of doctor-patient communication. The unit of analysis is the utterance or smallest meaningful string of words. All utterances are assigned to mutually exclusive categories. All behavior is merged into 16 clusters, nearly identical for doctor and patient. The affective dimension includes social behavior, agreement, paraphrase, verbal attention, showing concern, reassurance, and disagreement (of both patient and doctor). The instrumental dimension contains giving directions, asking clarification, asking questions (medical/therapeutic), asking questions (lifestyle/psychosocial), giving information (medical/therapeutic), giving information (lifestyle/psychosocial), counseling (doctor), other.

The consultations were rated by two trained observers by means of a computerized rating method, named CAMERA [33]. The interrater reliability (Pearson's correlation coefficient) was between 0.57 and $0.94,80 \%$ being above 0.80 . This score was satisfactory.

\subsection{Statistical analyses}

For comparison of two groups, $t$-tests were performed; for comparison of more than two groups, one-way and multiple 
range tests (Bonferroni) were performed. The RIAS categories were analyzed separately for both GPs and patients as percentages of all utterances, and the ratios affective/instrumental utterances were calculated. Additionally, stepwise regression analysis was performed on the most important RIAS categories. Finally stepwise discriminant analysis was performed to find the most important factors discriminating between the groups where fatigue was discussed and where fatigue was not discussed.

\section{Results}

\subsection{Fatigue and overall health}

Of all patients, $60 \%$ indicated having felt fatigued during the past 2 weeks. More women than men (66\% versus 51\%) reported that complaint, and more highly educated patients than average or low educated patients ( $70 \%$ versus $56 \%$ ), as well as more respondents aged between 19 and 50 years (66\% versus $54 \%$ ). When asked about the seriousness of the fatigue feelings on a scale between 0 and 10, the respondents' mean score was 5.9 (S.D. $=2.1$ ). The scores were divided normally, and there were no gender differences or other demographic differences. Of the fatigued patients, $42 \%$ indicated having mild feelings of fatigue (score between 1 and 5 ), while $58 \%$ considered themselves considerably fatigued (score between 6 and 10).

On (most) health indicators, the condition of mildly and considerably fatigued patients was worse than that of nonfatigued patients, the considerably fatigued group systematically reporting the worst health condition (see Table 1).

The more fatigued the patients were, the less fit they felt, the more they were bothered by emotional problems, the more limited they felt in daily and social activities, the more pain they experienced, and the worse their overall health was. The 'non-fatigued' and 'considerably fatigued' groups differed significantly by (almost) all health indicators, and so did the 'mildly fatigued' and 'considerably fatigued' patients. The 'non-fatigued' and 'mildly fatigued' groups differed by four of the seven indicators (feelings, daily activities, social activities, and overall health).

Men and women, except for one variable, did not differ regarding health conditions. Men indicated significantly more than women did that their overall health had become worse during the past 2 weeks $(X=3.24$ versus $X=2.92$; $t=3.96, P=0.000)$. No other demographic differences were manifested.

\subsection{Patients' expectations}

The major part of the patients' expectations of communication when consulting the GP referred to biomedical aspects, and a lesser part to diagnosis and treatment. However, a substantial number of the respondents expected a talk about psychosocial or emotional issues. In general, the more fatigued they were, the more they expected on all the three scales (biomedical, $r=0.17, P<0.001$; psychosocial, $r=0.29, P<0.001$; treatment, $r=0.11, P<0.05$ ).

On the item-level (see Table 2), there were no differences in the importance patients attached to technical-medical interventions during that particular visit, regarding (1) prescriptions and advice about medication, and (2) referrals. Major differences were manifested on all the items of the psychosocial scale ('feeling anxious', 'having emotional problems', 'having a difficult time', and 'explain emotional problems'). To illustrate, $9 \%$ of the non-fatigued patients expected help for emotional problems, compared to $28 \%$ of the considerably fatigued. And more than twice as many considerably fatigued patients felt anxious and expected some help, compared to the non-fatigued group ( $48 \%$ versus $23 \%)$. Both male and female fatigued patients expected more on the psychosocial scale.

Differences between considerably fatigued and non-fatigued patients on the biomedical items focused on 'talking about the problem', 'getting test results explained', 'getting the likely course of the problem explained', and 'to explain how serious my problem is'. Fatigued men expected more regarding biomedical aspects than fatigued women $\operatorname{did}(X=$ 16.39 versus $X=15.37, t=2.22, P<0.05)$. Fatigued men

Table 1

Health indicators and patients' level of fatigue

\begin{tabular}{|c|c|c|c|c|c|c|}
\hline \multirow[t]{2}{*}{ Indicator } & \multicolumn{2}{|c|}{ Non-fatigued } & \multicolumn{2}{|c|}{ Mildly fatigued } & \multicolumn{2}{|c|}{ Considerably fatigued } \\
\hline & Mean & S.D. & Mean & S.D. & Mean & S.D. \\
\hline Fitness ${ }^{* * * *}$ & 2.1 & $1.2^{\mathrm{b}}$ & 2.3 & $1.2^{\mathrm{b}}$ & 2.7 & 1.3 \\
\hline Feelings $^{* * *}$ & 1.7 & $1.1^{\mathrm{a}, \mathrm{b}}$ & 2.1 & $1.1^{\mathrm{b}}$ & 2.8 & 1.4 \\
\hline Daily activities ${ }^{* * * *}$ & 1.6 & $0.9^{\mathrm{a}, \mathrm{b}}$ & 2.0 & $1.0^{\mathrm{b}}$ & 2.9 & 1.4 \\
\hline Social activities ${ }^{* * * *}$ & 1.3 & $0.8^{\mathrm{a}, \mathrm{b}}$ & 1.6 & $0.9^{\mathrm{b}}$ & 2.4 & 1.2 \\
\hline Change in health ${ }^{*}$ & 3.0 & $0.8^{\mathrm{b}}$ & 3.0 & 1.0 & 3.2 & 1.0 \\
\hline Overall health ${ }^{* * * *}$ & 2.6 & $1.0^{\mathrm{a}, \mathrm{b}}$ & 3.1 & $1.0^{\mathrm{b}}$ & 3.8 & 0.8 \\
\hline Pain ${ }^{* * *}$ & 2.3 & $1.4^{\mathrm{b}}$ & 2.7 & $1.3^{\mathrm{b}}$ & 3.1 & 1.4 \\
\hline
\end{tabular}

a This score differs significantly from that of the group 'mildly fatigued'.

b This score differs significantly from that of the group 'considerably fatigued'.

${ }^{*} P<0.05$ (one-way ANOVA).

*** $P<0.001$ (one-way ANOVA). 
Table 2

Patients' expectations of the medical consultation, related to level of fatigue

\begin{tabular}{|c|c|c|c|}
\hline Expectancy items & $\begin{array}{l}\text { Non-fatigued, } \\
\% \text { (mean) }\end{array}$ & $\begin{array}{l}\text { Mildly fatigued, } \\
\% \text { (mean) }\end{array}$ & $\begin{array}{l}\text { Considerably fatigued, } \\
\% \text { (mean) }\end{array}$ \\
\hline \multicolumn{4}{|l|}{ Biomedical aspects } \\
\hline I would like Dr. to tell me what my symptoms mean* & $74(2.87)^{\mathrm{a}}$ & $82(3.14)$ & $78(3.02)$ \\
\hline I want Dr. to talk with me about my problem ${ }^{* *}$ & $66(2.68)^{\mathrm{b}}$ & $72(2.87)$ & $76(3.02)$ \\
\hline I want Dr. to explain the likely course of my problem ${ }^{* *}$ & $50(2.24)^{\mathrm{b}}$ & $48(2.28)^{\mathrm{b}}$ & $64(2.72)$ \\
\hline I want Dr. to explain how serious my problem is ${ }^{* *}$ & $54(2.36)^{\mathrm{b}}$ & $60(2.57)$ & $67(2.73)$ \\
\hline I want to be examined for the cause of my condition ${ }^{\dagger}$ & $51(2.27)^{\mathrm{b}}$ & $56(2.48)$ & $58(2.55)$ \\
\hline I would like Dr. to explain some test results ${ }^{*}$ & $58(2.46)^{\mathrm{b}}$ & $67(2.76)$ & $67(2.77)$ \\
\hline \multicolumn{4}{|l|}{ Psychosocial aspects } \\
\hline I feel anxious and would like Dr.'s help ${ }^{* * *}$ & $23(1.60)^{\mathrm{b}}$ & $32(1.85)^{\mathrm{b}}$ & $48(2.27)$ \\
\hline I have emotional problems for which I would like some help ${ }^{* * *}$ & $9(1.23)^{\mathrm{b}}$ & $11(1.30)^{\mathrm{b}}$ & $28(1.78)$ \\
\hline I am having difficult time and would like some support ${ }^{* * *}$ & $9(1.24)^{\mathrm{b}}$ & $17(1.43)^{\mathrm{b}}$ & $29(1.82)$ \\
\hline I want Dr. to explain my emotional problems ${ }^{* * * *}$ & $10(1.27)^{\mathrm{b}}$ & $12(1.31)^{\mathrm{b}}$ & $26(1.71)$ \\
\hline \multicolumn{4}{|l|}{ Diagnosis and treatment } \\
\hline I want a previous diagnosis confirmed & $24(1.61)^{\mathrm{b}}$ & $27(1.70)$ & $36(1.93)$ \\
\hline I want advice on a drug I am taking & $25(1.63)$ & $26(1.72)$ & $33(1.87)$ \\
\hline I want medication for my problem & $38(1.99)$ & $40(2.02)$ & $47(2.19)$ \\
\hline I want to be referred to a specialist & $26(1.70)$ & $25(1.67)$ & $29(1.77)$ \\
\hline
\end{tabular}

a This score differs significantly from that of the group 'mildly fatigued'.

b This score differs significantly from that of the group 'considerably fatigued'.

${ }^{*} P<0.05$ (one-way ANOVA).

** $P<0.01$ (one-way ANOVA).

${ }^{* * *} P<0.001$ (one-way ANOVA).

${ }^{\dagger} P<0.1$ (one-way ANOVA).

as a group attached more importance to 'information about the meaning of symptoms', 'examination for the cause of condition', and 'information about how serious the problem is'. No effects of the GP's gender or the patient's other demographic variables were noted to influence their expectations.

\subsection{Verbal behavior of patients}

Because fatigued patients were in poorer health and had higher expectations, instrumentally as well as emotionally, we may inquire about the way fatigued patients communicate about their problems and worries (see Table 3 ).

Most of the patients' utterances concerned the giving of medical and psychosocial information (64\%), followed by agreeing (14.2\%). The more fatigued the patients were, the more information they gave about their lifestyle and psychosocial aspects. Additionally, the higher the level of fatigue, the less the patients expressed their social behavior. Female patients as a group gave more psychosocial information compared to male patients $(17.9 \%$ versus $13.9 \%$, $t=-2.168, P<0.05)$. An effect of GP's gender on any category of patient behavior was absent.

The effect of level of fatigue and the patient's gender was also reflected in the length of the medical interview. While the mean length was $10.2 \mathrm{~min}$ (S.D. $=5.0 \mathrm{~min}$ ), the interviews with the considerably fatigued patients lasted longer (not fatigued $X=9.7$, mildly fatigued $X=9.7$, and considerably fatigued $X=11.4 ; F=4.860, P<0.01)$ than with the other two groups. And the interviews with female patients were longer than those with male patients $(X=10.6$ versus $X=9.4, t=-2.733, P<0.01$ ), especially in the mildly fatigued group.

Stepwise regression analysis showed that $20 \%$ of the variance of 'giving psychosocial information' was explained by the patient's expectations on the psychosocial and treatment issues (psychosocial, $\beta=0.476, P<0.001$; treatment, $\beta=-0.186, P<0.01)$. The variance in 'social talk' was explained mainly by the patient's expectations of psychosocial support $(\beta=-0.137, P<0.05)$ : the less healthy, the less affective behavior the patients showed. The length of the interview was mainly explained by patient's psychosocial expectations and health condition (psychosocial, $\beta=0.225, \quad P<0.001$; and health condition, $\beta=0.145, P<0.05)$.

\subsection{Verbal behavior of doctors}

As Table 4 shows, most verbal behavior of the GPs referred to 'giving information', 'agreeing', 'giving directions', and 'paraphrase', the major part being instrumental.

There was a substantial relation between the level of fatigue of patients and the GPs' behavior. As far as affective behavior is concerned, GPs paraphrased more in the case of considerably fatigued patients. Also more reassurance was given to the mildly fatigued. Regarding instrumental behavior, the analysis showed that GPs gave significantly fewer directions to considerably fatigued patients. In line with the 
Table 3

Affective and instrumental behavior of patients (\%) by level of fatigue

\begin{tabular}{|c|c|c|c|c|c|}
\hline Behavior category & Non-fatigued & Mildly fatigued & Considerably fatigued & $F$-value & $P$-value \\
\hline \multicolumn{6}{|l|}{ Affective behavior } \\
\hline Social behavior & 9.13 & 8.01 & 6.16 & 4.041 & 0.018 \\
\hline Agreement & 14.02 & 15.89 & 13.09 & & \\
\hline Paraphrase & 2.49 & 2.34 & 2.15 & & \\
\hline Verbal attention & - & - & - & & \\
\hline Showing concern & 1.06 & 1.20 & 1.35 & & \\
\hline Reassurance & 0.17 & - & 0.21 & & \\
\hline Disagreement & - & - & - & & \\
\hline Total affective behavior & 27.03 & 27.58 & 23.07 & 4.453 & 0.012 \\
\hline \multicolumn{6}{|l|}{ Instrumental behavior } \\
\hline Giving directions & 1.75 & 1.80 & 1.61 & & \\
\hline Asking clarification & 0.83 & 0.95 & 0.68 & & \\
\hline \multicolumn{6}{|l|}{ Asking questions } \\
\hline Medical/therapeutical & 3.79 & 4.14 & 3.60 & & \\
\hline Lifestyle/psychosocial & 0.40 & 0.33 & 0.50 & & \\
\hline \multicolumn{6}{|l|}{ Gives information } \\
\hline Medical/therapeutical & 48.08 & 46.47 & 47.75 & & \\
\hline Lifestyle/psychosocial & 14.10 & 15.01 & 19.81 & 3.358 & 0.036 \\
\hline Other utterances & 3.69 & 3.44 & 2.80 & & \\
\hline Total instrumental behavior & 72.97 & 72.42 & 76.93 & 4.453 & 0.012 \\
\hline
\end{tabular}

patients' behavior, GPs gave slightly more lifestyle and psychosocial information to these patients. Finally, GPs counseled significantly more on psychosocial or lifestyle issues when patients were considerably fatigued.

Is there any effect of the patient's gender on the GP's verbal behavior? GPs gave less verbal attention to male patients compared to female patients $(0.7 \%$ versus $1.2 \%$, $t=-2.88, P<0.01)$. Further, male patients received more directions $(11.8 \%$ versus $10.2 \%, t=2.308, P<0.05$ ), while female patients received more information on lifestyle/psychosocial (3.7\% versus $5.5 \%, t=-2.026, P<0.05)$. This remains parallel with the results of female patients talking more about lifestyle and psychosocial issues.

The main differences in verbal behavior, however, were manifested between male and female GPs (see also Table 4). Female doctors showed relatively more affective behavior, by agreeing and by giving verbal attention and reassurances, while male doctors had a tendency to display more social behavior, however the difference is not significant. Male GPs demonstrated relatively more instrumental behavior, by giving more information (medical as well as psychosocial), but fewer directions. Interesting was the interaction effect of the GP's gender and the patient's level of fatigue on GP's affective behavior $(F=3.663, P=0.027)$ : male GPs behaved more instrumentally if the patient's level of fatigue increased, whereas female GPs behaved more effectively.

Although there was no GP's gender effect on the length of the interview, it is noteworthy that while interviews of male GPs with male patients were as long as with female patients
( $X=9.86$ versus $X=10.15$ ), the interviews of female GPs with female patients were much longer than the interviews with the male patients $(X=11.16$ and $X=8.80$, $P<0.001)$. These differences were visible especially in the mildly fatigued group.

Stepwise regression analysis showed that the variance in GPs' affective behavior was mainly explained by their gender $(\beta=0.219, P<0.001)$, and by patients' psychosocial expectations $(\beta=0.169, P<0.01)$.

\subsection{Fatigue discussed or not}

Are there any differences in communication styles between consultations during which fatigue is openly discussed and those during which it is not? First, it was remarkable that out of the 383 consultations of fatigued patients, only in $6 \%(n=23)$ fatigue was discussed with the GP (4 mildly fatigued patients and 19 considerably fatigued patients). The more fatigued patients were $(r=0.24$, $P<0.01$ ), the poorer was their general health condition $(r=0.24, P<0.000)$, the more psychosocial talk they expected $(r=0.23, P<0.01)$, and the greater the chance was that fatigue was discussed. GPs' or patients' gender did not matter. The percentage of GPs' affective behavior was slightly higher in the discussed group (33.5\% versus $38 \%$, $t=-1.733, P<0.1)$.

It is interesting to see the differences in GPs' affective behavior in different dyads (see Table 5). While in the other three dyads no differences were found between the discussed 
Table 4

Affective and instrumental behavior of GPs (\%) by patient's level of fatigue and GP's gender

\begin{tabular}{|c|c|c|c|c|c|c|c|c|c|c|}
\hline \multirow[t]{2}{*}{ Patient's level of fatigue } & \multicolumn{4}{|c|}{ Male GPs } & \multicolumn{4}{|c|}{ Female GPs } & \multirow[t]{2}{*}{$F$-value } & \multirow[t]{2}{*}{$P$-value } \\
\hline & $\begin{array}{l}\text { Non- } \\
\text { fatigued }\end{array}$ & $\begin{array}{l}\text { Mildly } \\
\text { fatigued }\end{array}$ & $\begin{array}{l}\text { Considerably } \\
\text { fatigued }\end{array}$ & Total & $\begin{array}{l}\text { Non- } \\
\text { fatigued }\end{array}$ & $\begin{array}{l}\text { Mildly } \\
\text { fatigued }\end{array}$ & $\begin{array}{l}\text { Considerably } \\
\text { fatigued }\end{array}$ & Total & & \\
\hline \multicolumn{11}{|l|}{ Affective behavior } \\
\hline Social behavior & 8.54 & 7.24 & 6.78 & 7.56 & 6.80 & 7.29 & 5.33 & 6.40 & 18.126 & 0.000 \\
\hline Agreement & 12.09 & 12.16 & 11.72 & 11.98 & 15.28 & 15.52 & 17.59 & 16.17 & & \\
\hline Paraphrase $^{\mathrm{a}}$ & 10.24 & 8.39 & 9.77 & 9.55 & 9.26 & 9.18 & 12.19 & 10.28 & 19.237 & 0.000 \\
\hline Verbal attention & 0.73 & 0.39 & 0.63 & 0.60 & 1.04 & 1.43 & 1.95 & 1.47 & & \\
\hline Showing concern & 0.67 & 0.34 & 0.45 & 0.50 & 0.48 & 0.28 & 0.50 & 0.44 & 12.473 & 0.000 \\
\hline Reassurance $^{\mathrm{b}}$ & 0.69 & 0.92 & 1.26 & 0.95 & 1.28 & 2.47 & 1.44 & 1.64 & & \\
\hline Disagreement & - & - & - & - & - & - & - & - & & \\
\hline Total affective behavior & 32.96 & 29.48 & 30.63 & 31.16 & 34.15 & 36.22 & 39.02 & 36.41 & 19.677 & 0.000 \\
\hline \multicolumn{11}{|l|}{ Instrumental behavior } \\
\hline Giving directions $^{c}$ & 9.74 & 11.10 & 9.04 & 9.89 & 12.71 & 11.54 & 9.57 & 11.29 & 4.587 & 0.033 \\
\hline Asking clarification & 1.57 & 1.54 & 1.65 & 1.59 & 1.56 & 1.71 & 1.45 & 1.56 & & \\
\hline \multicolumn{11}{|l|}{ Asking questions } \\
\hline Medical/therapeutical & 7.76 & 8.03 & 7.09 & 7.61 & 8.50 & 7.48 & 7.41 & 7.85 & & \\
\hline Lifestyle/psychosocial & 2.27 & 2.46 & 2.98 & 2.57 & 2.13 & 2.81 & 2.50 & 2.44 & & \\
\hline \multicolumn{11}{|l|}{ Gives information } \\
\hline Medical/therapeutical & 27.94 & 31.55 & 27.71 & 28.89 & 26.60 & 25.65 & 25.55 & 25.98 & 4.301 & 0.039 \\
\hline Lifestyle/psychosocial $^{\mathrm{d}}$ & 5.27 & 4.55 & 8.05 & 6.02 & 2.90 & 4.14 & 4.89 & 3.93 & 4.561 & 0.033 \\
\hline \multicolumn{11}{|l|}{ Counsels } \\
\hline Medical/therapeutical & 7.97 & 7.14 & 7.53 & 7.58 & 7.34 & 6.60 & 6.10 & 6.71 & & \\
\hline Lifestyle/psychosocial $^{\mathrm{e}}$ & 0.77 & 0.51 & 1.37 & 0.91 & 0.43 & 0.46 & 0.95 & 0.62 & & \\
\hline Other utterances & 3.75 & 3.65 & 3.95 & 3.79 & 3.68 & 3.40 & 2.54 & 3.20 & & \\
\hline Total instrumental behavior & 67.04 & 70.52 & 69.37 & 68.84 & 65.85 & 63.78 & 60.98 & 63.59 & 19.677 & 0.000 \\
\hline
\end{tabular}

Effect of patient's level of fatigue on GP's behavior.

a Paraphrase: $F=5.972, P=0.003$ (non-fatigued $X=9.74$, mildly fatigued $X=8.76$, considerably fatigued $X=11.00$ ).

${ }^{\mathrm{b}}$ Reassurance: $F=3.662, P=0.027$ (non-fatigued $X=0.99$, mildly fatigued $X=1.65$, considerably fatigued $X=1.35$ ).

${ }^{\mathrm{c}}$ Giving directions: $F=4.088, P=0.018$ (non-fatigued $X=11.25$, mildly fatigued $X=11.31$, considerably fatigued $X=9.31$ ).

${ }^{\mathrm{d}}$ Giving info, lifestyle/psychosocial: $F=2.471, P=0.086$ (non-fatigued $X=4.06$, mildly fatigued $X=4.36$, considerably fatigued $X=6.45$ ).

${ }^{\mathrm{e}}$ Counseling, lifestyle/psychosocial: $F=3.508, P=0.031$ (non-fatigued $X=0.60$, mildly fatigued $X=0.49$, considerably fatigued $X=1.16$ ).

and not discussed group, in the female/female dyad the differences between the two groups were high.

Stepwise discriminant analysis revealed that the patient's health condition accounted most for the difference between the groups where fatigue was 'discussed' or was 'not discussed' (Wilks' $\lambda=0.928, P<0.001 ; 95 \%$ of the original grouped cases correctly classified).

Table 5

GP's affective behavior related to 'fatigue discussed or not' (\%)

\begin{tabular}{lll}
\hline Dyad type & $\begin{array}{l}\text { Fatigue not } \\
\text { discussed (\%) }\end{array}$ & $\begin{array}{l}\text { Fatigue } \\
\text { discussed (\%) }\end{array}$ \\
\hline GP male/patient male & 29.0 & 31.8 \\
GP male/patient female & 30.7 & 31.1 \\
GP female/patient male & 37.9 & 40.2 \\
GP female/patient female & 36.6 & 54.0 \\
\hline
\end{tabular}

\section{Discussion}

This study confirms our first hypothesis that, according to earlier findings, fatigue is a common health problem in the population and that it is seldom explicitly on the agenda in the medical interview $[2,3]$. As other studies suggest, fatigue is under-recognized in general practice. More women than men indicate having fatigue problems. Especially highly educated women between 19 and 50 years of age seem to be at risk. If women face a double task of combining employment with caring for young children, they are more vulnerable to the risk of feeling 'burned out' $[8,10]$. By almost all health indicators our study also confirmed that fatigued patients' health is worse than that of non-fatigued patients. These results are in accordance with earlier findings [8]. If fatigue is discussed, it is mainly because of the poorer health condition of the patients, and because they expect more emotional support. 
The second hypothesis is confirmed, i.e. both fatigued men and women expect more from the psychosocial aspects of the medical visit than non-fatigued men and women do. The same can be said of the biomedical aspects of the visit. Fatigued male patients attach more importance to biomedical aspects of the visit than non-fatigued male patients, and all female patients do.

Although fatigue is seldom discussed during the medical consultation, this does not necessarily mean that relevant related issues are not communicated. The results show that our third hypothesis is confirmed in that the more fatigued the patients are, the less prone they are to perform social talk and the more they talk about psychosocial issues. Women talk more about psychosocial issues than men do. The giving of psychosocial information can be explained mainly by the patients' emotional expectations; the more they expect emotionally, the more they will talk about psychosocial or lifestyle issues. These results do also confirm that fatigue is associated with mental distress [12]. Although the level of mental distress was not otherwise measured, e.g. by a General Health Questionnaire or otherwise, there is certainly indication that emotional problems were addressed and discussed in these interviews.

The fourth hypothesis seems partly confirmed. While GPs as a group accommodate their behavior towards the more fatigued patients by giving more psychosocial information and doing more counseling, they are not more affective in their behavior towards them than to non-fatigued patients. However, substantial differences between male and female GPs emerged. These differences conform to other studies, which state that female doctors are more affective and in that sense more sensitive to the patients' needs [16-21]. In our study, female doctors as a group are more sensitive to the needs of all patients, and thus also those who are fatigued. And, if fatigue is discussed, female doctors are especially sensitive to female patients. However, as we saw, discussing fatigue is not more frequent on the female doctors' agenda than it is on their male colleagues'. The differences between the dyad 'female GP and female patient' and the other three dyads may be understood in terms of 'gendered' expectations of the patients in combination with the 'gendered' behavior of the GPs. Specific expectations of female patients combined with a more empathic attitude of female GPs may result in an interaction pattern that is characterized by intensive exchange of medical and psychosocial information and expression of feelings and worries. As far as affective behavior and speaking time are concerned, the relation is more patient-centered and more symmetric, which confirms other findings $[18,34,35]$. Apart from expecting more concerning psychosocial issues, male fatigued patients expect also more concerning biomedical issues. When realizing that male GPs are somewhat more instrumental, this will help in understanding why in the case of male GPs fatigue is discussed less effectively, and in the case of the dyad 'female GP and male patient' the percentage indicating affective behavior in the group 'fatigue discussed' is in between
(Table 5). Again it is confirmed that in medical communication, gender-specific expectations and communication styles are produced and reproduced continuously.

One may question what these findings mean in terms of quality of health care. As we mentioned, effective behavior of the physician contributes substantially to patient satisfaction and quality of care [5], by fulfilling patients' need to be recognized and understood [15]. If this holds true, the female patients consulting the female GPs should be most satisfied. Although we did not report it in Section 3, data about patients' satisfaction did not manifest any differences between the several groups in this study. This means that it is difficult to draw conclusions for this specific sample. On the other hand, findings in The Netherlands suggest that if patients can choose between a male or female doctor, a substantial number of them prefer a female doctor [22].

Another interesting issue is the relation between the seriousness of patients' illness and the way the medical communication is styled by both participants. Hall et al. [13] reported that the sicker or the more emotionally distressed patients were, the more complicated medical communication became. Among other things, they established that there was less social talk between doctors and sicker patients, that they tended to disagree with each other, exchanged more negative emotions, and that the relation was more ambiguous than with less sick patients. Less healthy patients also provided more biomedical and psychosocial information, and engaged in a more emotionally concerned talk. Some of these findings are confirmed in our study, although no more negative communication was observed. The differences in results may be explained partly because of the methods chosen, and/or because of the differences in medical settings - the American outpatients clinic and the Dutch general practice. Dutch GPs have received their professional training as medical generalists, and as gatekeepers in the Dutch health care system. The latter means that they are supposed to have a special eye for psychosocial problems of their patients.

\subsection{Limitations of the study}

Before discussing the implications of these results, we have to address some methodological issues. The patient questionnaires used here were mostly reliable and valid, except for the sub-scale 'treatment' of the patients' consultation expectations. If questions were asked about the level of patients' mental distress, the study could have gained importance. Obviously, the value of this study consists in the insight into the role of gender differences in medical communication in the case of fatigue, obtained by using the RIAS observation system. It has already been mentioned that the reliability of RIAS was satisfactory. In this study, the RIAS results were reported proportionally (in relative percentages) and not in absolute numbers. This way of reporting conforms to most of the studies in this tradition $[23,24]$. Sometimes, the results of these ways of presenting 
may differ from each other, however a check on this revealed no major differences in results. Referring to the validity of RIAS, it can be said that RIAS measures just one level of communication, the affective and instrumental behavior which is restricted to frequency analysis. It is advisable to present case studies in order to further unravel the specific interactional patterns in the process of presenting complaints, the expression of worries, and the (re)formulation of complaints. RIAS could then be applied in combination with qualitative methods and/or sequential analysis [36].

Since our study emphasized gender differences, an equal number of male and female GPs was used. In reality, the male/female ratio of GPs is 80/20 in The Netherlands, which means that the communication patterns of the male GPs are the majority. Furthermore, because the group of patients with whom fatigue was actually discussed in the consultation room was very small, these results need to be interpreted carefully.

\subsection{Practice implications}

As this study shows, gender differences do matter. Therefore, it is necessary to use a gender-sensitive approach in medical communication research. Besides quantitative methods, it is recommended to pay more attention to the individual and to the joint efforts of the patient and the GP in the process of organizing the medical conversation and negotiating the definition of complaints [37,38]. Empirical analysis of records of the medical interaction seems quite promising [39], as established in the tradition of qualitative research on institutional interaction [40,41]. It is, for instance, interesting how different forms of disclosures and different forms of empathy are organized in the interaction between the GP and the patient. Arguably, the insight in the specific communication patterns will help to unravel the complex communication in the case of fatigued patients.

The findings of this study do also have implications for medical practice. As long as gender-specific communication patterns are produced and reproduced, male and female health care providers have to be made conscious of their own communication styles, their strengths and weaknesses, and their special effect upon patients with fatigue complaints. What seems necessary is physician training in interpersonal communication, emphasizing those aspects of communication that will facilitate patients' communication of their worries and emotions related to fatigue. Fatigued patients need to realize the relevance of communicating their worries in relation to fatigue and its possible beneficial effects on their general health condition. It is possible that patients may also have learned not to talk about the issues during medical consultations because their doctors do not respond. In any case, doctors may not know what to do with patients' complaints about fatigue, and may selectively ignore cues to exploring these complaints, or even become irritated [13]. If they do not know what to do about the problem, they tend to ignore it. Strathdee [42] has formulated some important conditions for dealing with sicker or mentally distressed patients, pointing to education and supervision especially with regard to the assessment and management of patients with fatigue complaints, and ways these symptoms are related to biological, psychological or social factors. In order to realize the specific demands in consulting these patients, doctors should undergo group teaching while watching their own consultations on video and receiving group feedback [43].

\section{References}

[1] Lewis G, Wessely S. The epidemiology of fatigue: more questions than answers. J Epid Com Health 1992;46:92-7.

[2] Morrell D. Symptoms perceived and recorded by patients. J R Coll Gen Pract 1976;33:191-8.

[3] Lamberts H, Brouwer HJ, Marinus AFM, Hofmans-Okkes IM. The use of ICPC in the transition project: episode-oriented epidemiology in general practice. In: Lamberts $\mathrm{H}$, Wood M, Hofmans-Okkes I, editors. The international classification of primary care in the European community with a multilayer sample. Oxford: Oxford University Press; 1993. p. 45-61.

[4] Foets M, Sixma H. Een nationale studie van ziekten en verrichtingen in de huisartspraktijk: basisrapport gezondheid en gezondheidsgedrag in de praktijkpopulatie (Dutch national survey of morbidity and interventions in general practice: key report health and health behavior in general practice). Utrecht: Nivel; 1991.

[5] Bensing J, Hulsman R, Schreurs K. Vermoeidheid: een chronisch probleem (Fatigue: a chronic problem). Medisch Contact 1996;51(4): 123-4.

[6] de Rijk AE. Fatigue in general-practice patients: an empirical study of fatigue in general practice and the development of the qualityquantity model for understanding fatigue. Dissertation, Utrecht University. Enschede: Ipskamp Print Partners; 1999.

[7] Harari D, Glas G. Chronische moeheid, testcase voor de geneeskunde (Chronic fatigue, testcase for medicine). Tijdschrift voor Psychiatrie 1993;35:51-63.

[8] Bensing JM, Hulsman RL, Schreurs KMG. Gender differences in fatigue: biopsychosocial factors relating to fatigue in men and women. Med Care 1999;37:1078-83.

[9] Meijman T, Schaufeli W. Psychische vermoeiheid en arbeid: ontwikkelingen in de A\&O-psychologie (Psychological fatigue and work: developments in industrial and organizational psychology). De Psycholoog 1996;31:236-41.

[10] Rietbergen C, van Vliet K, Vrouwen en de WAO. Een verhaal apart? In: Hortulanus R, Machielse A, editors. De waarde van werk: het sociaal debat, deel 4 (The value of work: the social debate). Gravenhage: Elsevier; 2001. p. 89-105.

[11] Lamberts H. In het huis van de huisarts (In the home of the general practitioner). Lelystad: Meditekst; 1991.

[12] Fuhrer R, Wessely S. The epidemiology of fatigue and depression: a French primary-care study. Psychol Med 1995;25:895-905.

[13] Hall JA, Roter DL, Milburn MA, Daltroy LH. Patients' health as a predictor of physician and patient behavior in medical visits: a synthesis of four studies. Med Care 1998;34:1205-18.

[14] Stewart MA, Brown JB, Weston WW, McWinney IR, McWilliam CL, Freeman TR. Patient centered medicine: transforming the clinical method. London: Sage; 1995.

[15] Engel GL. How much longer must medicine's science be bound by a seventeenth century world view? In: White $\mathrm{K}$, editor. The task of medicine: dialogue at Wickenburg. Menlo Park (CA): The Henry Kaiser Foundation; 1988. p. 113-36.

[16] Hall JA, Roter DL. Medical communication and gender: a summary of research. J Gender Spec Med 1998;1:39-42. 
[17] Meeuwesen L, Schaap C, van der Staak C. Verbal analysis of doctorpatient communication. Soc Sci Med 1991;32:1143-50.

[18] Meeuwesen L. Sekseverschillen in de communicatie tussen arts en patiënt. In: Lagro-Janssen T, Noordenbos G, editors. Sekseverschilen in ziekte en gezondheid (Gender differences in illness and health). Nijmegen: SUN; 1997. p. 63-77.

[19] Roter D, Lipkin M, Korsgaard A. Sex differences in patients' and physicians' communication during primary care medical visits. Med Care 1991;29:1083-93.

[20] Bensing JM, van den Brink-Muinen A, de Bakker DH. Gender differences in practice style: a Dutch study of general practitioners. Med Care 1993;31:219-29.

[21] van den Brink-Muinen A. Gender, health and health care in general practice. Dissertation. Utrecht: Nivel; 1996.

[22] Kerssens JJ, Bensing JM, Andela MG. Patient preference for genders of health professionals. Soc Sci Med 1997;44:1531-40.

[23] van den Brink-Muinen A, Verhaak P, Bensing J, Bahrs O, Deveugele M, Gask L, et al. The Eurocommunication study: an international comparative study in six European countries on doctor-patient communication in general practice. Utrecht: Nivel; 1999.

[24] van den Brink-Muinen A, Verhaak P, Bensing J, Bahrs O, Deveugele M, Gask L, et al. Doctor-patient communication in different European health care systems: relevance and performance from the patients' perspective. Pat Educ Couns 2000;39:115-27.

[25] de Rijk A, Schreurs K, Bensing J. Patient factors related to the presentation of fatigue complaints: results from a women's general health care practice. Women Health 2000;30:121-6.

[26] de Rijk A, Schreurs K, Bensing J. Complaints of fatigue: related to too much as well as too little external stimulation? J Behav Med 1999;22:549-73.

[27] van der Velden J, de Bakker DH, Claessens AAMC, Schellevis FG. Dutch national survey of general practitioner: morbidity in general practice. Utrecht: Nivel; 1992.

[28] van Weel C, van König-Zahn C, Touw-Otten F. Measuring functional health status with the COOP/WONCA charts: a manual. The Netherlands: WONCA/ERGHO/NCH/University of Groningen; 1995.
[29] Sixma HJ, Kerssens JJ, van Kampen C, Peters L. Quality of care from the patients' perspective: from theoretical concept to a new measuring instrument. Health Expect 1998;1:82-95.

[30] Valori R, Woloshynowych M, Bellenger N, Aluvihare V, Salmon P. The patient requests form: a way of measuring what patients want from their general practitioner. J Psych Res 1996;40:87-94.

[31] Roter DL. The Roter method of interaction process analysis: RIAS manual. Baltimore: John's Hopkins University; 1991.

[32] Bales RF. Interaction process analysis. Cambridge: Addison-Wesley; 1950.

[33] van der Vlugt MJ, Kruk MR, van Erp AMM, Geuze RH. CAMERA: a system for fast and reliable acquisition of multiple ethological records. Behav Res Method Instrum Comput 1992;24:147-9.

[34] van den Brink-Muinen A, Bensing JM, Kerssens JJ. Gender and communication style in general practice: differences between women's health care and regular health care. Med Care 1998;36:100-6.

[35] Roter DL, Hall JA. How physician gender shapes the communication and evaluation of medical care. Mayo Clin Proc 2001;76:673-6.

[36] Roter DL. The enduring and evolving nature of the patient-physician relationship. Pat Educ Couns 2000;39:5-15.

[37] Freidson E. Profession of medicine: a study of the sociology of applied knowledge. New York: Dodd, Mead \& Company; 1970.

[38] DiMatteo MR, DiNicola DD. Achieving patient compliance. New York: Pergamon Press; 1982.

[39] Tates K. Doctor-parent-child communication. Dissertation. Utrecht: Nivel/Utrecht University; 2001.

[40] Heritage J. Conversation analysis and institutional talk: analysing data. In: Silverman D, editor. Qualitative research: theory, method and practice. London: Sage; 1997. p. 161-82.

[41] Potter J, Edwards D. Discursive social psychology. In: Robinson WP, Giles $\mathrm{H}$, editors. The new handbook of language and social psychology. Chichester: Wiley; 2001. p. 103-18.

[42] Strathdee G. Primary care-psychiatry interaction: a British perspective. Gen Hosp Psych 1987;9:102-10.

[43] Gask L, Goldberg D, Boardman J, et al. Training general practitioners to teach psychiatric interviewing skills: an evaluation of group training. Med Educ 1991;25:444-51. 